\title{
Effect of Shoulder Diameter on the Force Generation, Microstructure and Mechanical Properties of Friction Stir-Brazed Aluminium Alloy and Copper with Ultrahigh Rotation Speed
}

\author{
Yang Zhou ${ }^{1,2} \cdot$ Shujin Chen ${ }^{2} \cdot \mathrm{Di} \mathrm{Wang}^{2} \cdot \mathrm{Ruifeng}^{\mathrm{Li}}{ }^{2} \cdot \mathrm{Bin} \mathrm{Liu}^{2} \cdot$ Juan $\mathrm{Pu}^{2} \cdot$ Zhidong Yang $^{2}$ \\ Received: 10 April 2019 / Revised: 15 August 2019 / Published online: 9 November 2019 \\ (C) The Chinese Society for Metals (CSM) and Springer-Verlag GmbH Germany, part of Springer Nature 2019
}

\begin{abstract}
Friction stir brazing with ultrahigh rotation speed was applied to 6061 aluminium alloy-pure copper lap joints with the aid of zinc foil. The effects of different shoulder diameters from 7 to $15 \mathrm{~mm}$ on the microstructure and mechanical properties of $\mathrm{Al} / \mathrm{Cu} \mathrm{FSB}$ joints were investigated along with the temperature and resistance of the friction tool. The oscillation of forward resistance and lateral force was related to the flow of the plastic metal and contributed to obtain a good appearance during the welding process. From the appearance of the welded joints, it was obvious that the phase difference between the forward resistance and lateral force had a significant influence on the joint characteristics. Obvious scale-like ripples appeared on the weld area when a sharp angle in the phase difference curve existed. Additionally, with a lower axial force and oscillation assistance, a satisfactory joint could be obtained. The results of the shear strength of the brazed joint showed that the shoulder with a $12 \mathrm{~mm}$ diameter yielded the highest shear strength. Meanwhile, the zinc foil in the middle melted completely and formed finely dispersed $\mathrm{CuZn}_{5} \mathrm{Al}-\mathrm{Zn}$ eutectic structures at the $\mathrm{Al}-\mathrm{Cu}$ interface.
\end{abstract}

Keywords Friction stir brazing $\cdot$ Ultrahigh rotation speed $\cdot \mathrm{Zn}$ foil $\cdot$ Forward resistance $\cdot$ Lateral force

\section{Introduction}

Dissimilar joints of aluminium and copper show great advantages in electrical applications owing to their higher electrical and heat conductivities, corrosion resistance and mechanical properties [1-4]. However, some defects can occur when using conventional fusion welding methods, such as brittle intermetallic compounds (IMC) and pores, due to the different thermal, chemical and mechanical properties of the metals [5-7]. Due to the inefficiency and complicacy of fusion welding methods, more and more studies are focused on alternate welding methods, such as solidstate welding including explosive welding and brazing. However, these alternate processes have still shown some

Shujin Chen

chenshujin7120@126.com

1 School of Computer Science and Engineering, Jiangsu University of Science and Technology, Zhenjiang 212003, China

2 School of Material Science and Engineering, Jiangsu University of Science and Technology, Zhenjiang 212003, China disadvantages in relevant research. For example, explosive welding is dangerous and inconvenient for joining $\mathrm{Al}$ and $\mathrm{Cu}$ plates [8]. Brazing in a furnace is one of the most common methods for joining $\mathrm{Cu} / \mathrm{Al}$ (dissimilar metals). Conventional furnace brazing of $\mathrm{Al}-\mathrm{Cu}$ lap joints using a $0.2 \mathrm{~mm}$ $\mathrm{Zn}$ foil filler was carried out at $450{ }^{\circ} \mathrm{C}, 470{ }^{\circ} \mathrm{C}$ (for $3 \mathrm{~min}$ ), and $530{ }^{\circ} \mathrm{C}$ (for $5 \mathrm{~min}$ ) under $0.3 \mathrm{MPa}$ in a flowing argon atmosphere. However, thick $\mathrm{Al}_{2} \mathrm{Cu} \mathrm{IMC}$ layers were found because of the too long metallurgic reaction time during flame brazing [9-11].

As a solid-state joining technology, friction stir welding (FSW) is expected to solve the above problems. Through traditional $\mathrm{FSW}$ of $\mathrm{Al} / \mathrm{Cu}$ assemblies, a high-quality joint could be obtained under the condition of a low rotation speed and large axial force [12]. However, the problems of pin tool wear and unsuitability for ultrathin plates have not been solved completely, which motivates the further study on using friction stir brazing (FSB) to join $\mathrm{Al}$ and $\mathrm{Cu}$.

Recent studies have shown that satisfactory FSB joints of $\mathrm{Al} / \mathrm{Cu}$ can be obtained when zinc is used as an interlayer. It has been determined that zinc has excellent abilities to remove the oxide film in air and eliminate both the thick solidified microstructure and resultant solidification cracking 
[13]. Kuang et al. [14] reported that the thickness of the interlayer at the centre of the $\mathrm{Al} / \mathrm{Cu}$ joint decreased clearly by increasing the rotation speed to $2000 \mathrm{rpm}$. At the same time, Huang et al. [15] found that the change in the travel speed also has a significant effect on the thickness of the interlayer. Abdollah-Zadeh et al. [16] obtained satisfactory $\mathrm{Al} / \mathrm{Cu}$ lap joints (rotation speed $1750 \mathrm{rpm}$, welding temperature $450{ }^{\circ} \mathrm{C}$ ). The maximum tensile strength of the joint reached $1447 \mathrm{~N}$. By observing the tensile fracture morphology, fracture was found to occur in the heat-affected zone of upper aluminium alloy. To further improve the joint quality, an ultrasound-assisted friction stir brazing method has been adopted. The results showed that the vibration of ultrasonic waves was beneficial to the substitution of $\mathrm{Cu}-\mathrm{Zn}$ IMC in place of harmful Al-Cu IMC [17], while ultrasonic waves also brought inconveniences to implementation.

However, few systematic studies focused on the influence of different parameters (shoulder diameter, rotation speed and travel speed) when welding dissimilar $\mathrm{Al}$ and $\mathrm{Cu}$ sheets with zinc as the interlayer, especially at high rotation speeds. Ultrahigh rotation speeds and low axial forces could cause different $\mathrm{Zn}$ behaviours [18]. Chen et al. [19] found that the highest axial force was only $200 \mathrm{~N}$, which was much lower than that in traditional FSW, under the condition that the rotation speed was $16,000 \mathrm{rpm}$ and the travel speed was $110 \mathrm{~mm} / \mathrm{min}$. Additionally, it is expected that a high rotation speed also brings vibration during welding. Obviously, whether the above behaviours would affect the welded joint is worth further study.

In this study, ultrahigh rotation speed FSB with pure Zn as a filler metal was used to obtain $\mathrm{Cu} / \mathrm{Al}$ brazed joints. An orthogonal experimental method was applied to discuss the different parameters' (tool shoulder diameter, rotation speed and travel speed) effects on the welding quality. Furthermore, the effects of the forces and their oscillation during the welding process on the $\mathrm{Al} / \mathrm{Cu} \mathrm{FSB}$ joints were investigated.

\section{Experimental}

\subsection{Experimental Equipment}

As shown in Fig. 1, a FSW machine with a maximum rotation speed of 18,000 rpm was used in this study. The friction tools used were pin-less and made of $\mathrm{H} 13$ quenched and tempered steel, and the inclination was $1.5^{\circ}$ during the welding process.

To facilitate parameter detection during the welding process, such as the forward resistance and lateral force, a two-layer structure was specially designed, as shown in Fig. 1b. In Fig. 1c, d, the upper layer was used to detect the forward resistance, and the lower layer was used to detect the lateral force. To ensure the direction of the detected forces, the forward and lateral guide rails were located at the upper and lower levels, respectively. The forward resistance and lateral force sensors were located in both the upper and lower layers and had the maximum range of 1000 N. As shown in Fig. 2a, the measurement of axial force was relatively simple, and the corresponding pressure sensor with a maximum range of $2000 \mathrm{~N}$ was placed under the working surface.

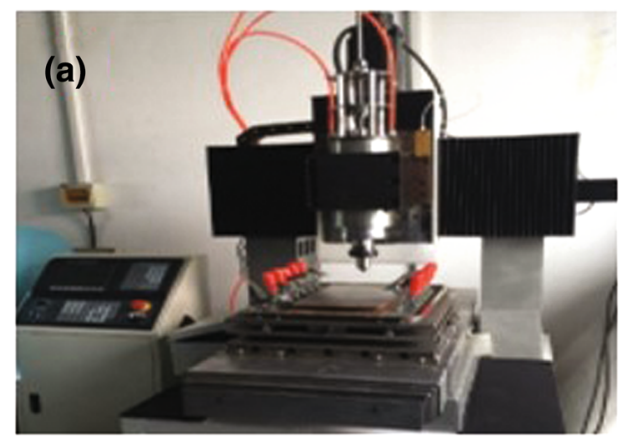

(c)

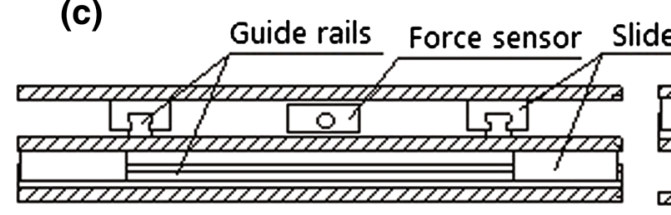

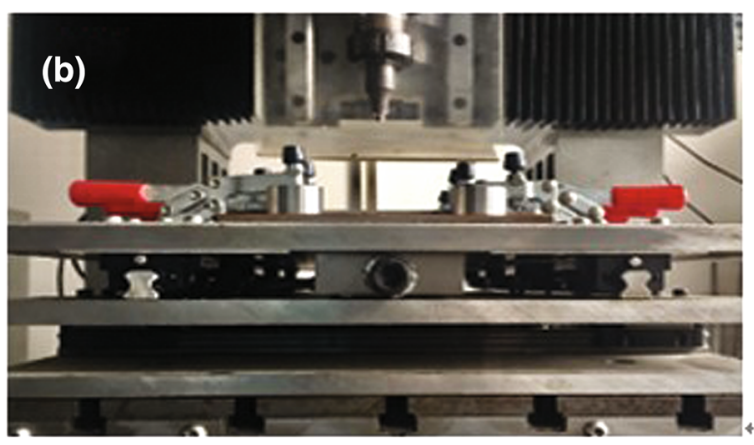

(d)

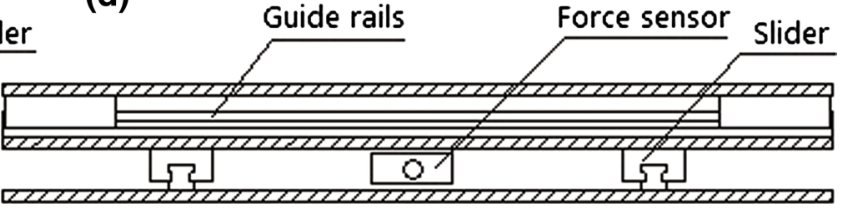

Fig. 1 High-speed friction stir welding equipment. FSW machine a, detection device $\mathbf{b}$, detection principle of forward resistance $\mathbf{c}$, detection principle of lateral force $\mathbf{d}$ 

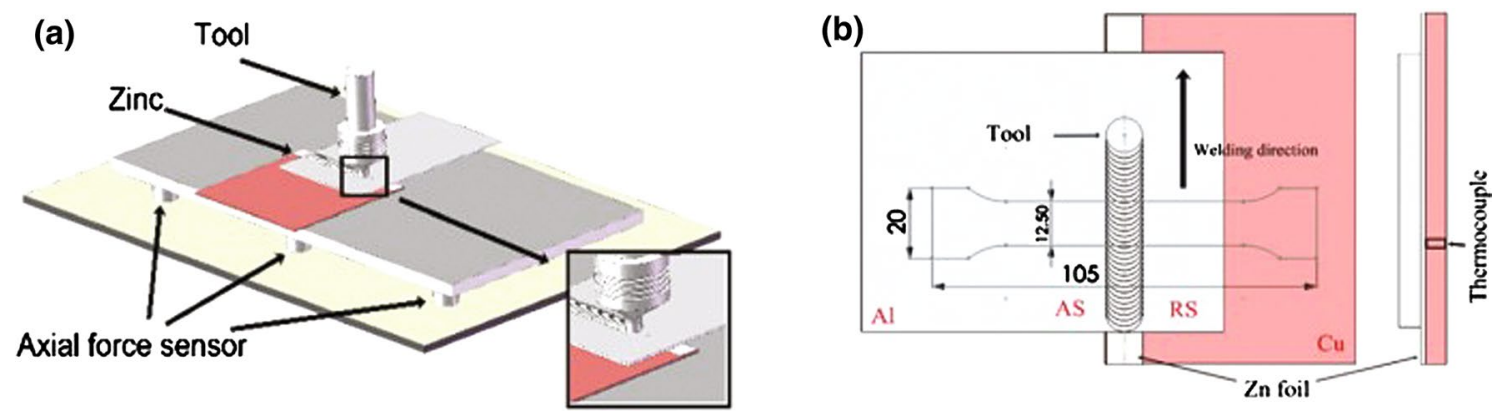

Fig. 2 Schematic of the FSW process a, position of the shear test sample, which are also temperature detection points measured via thermocouple b

Table 1 Base material chemical composition (wt\%)

\begin{tabular}{lllllllll}
\hline Material & $\mathrm{Al}$ & $\mathrm{Cu}$ & $\mathrm{Zn}$ & $\mathrm{Si}$ & $\mathrm{Fe}$ & $\mathrm{Mn}$ & $\mathrm{Mg}$ & $\mathrm{Cr}$ \\
\hline $6061-\mathrm{T} 6$ & $\mathrm{Bal}$ & 0.28 & 0.05 & 0.62 & 0.5 & 0.1 & 1 & 0.19 \\
\hline
\end{tabular}

\subsection{Experimental Materials}

The materials used for brazing were 6061 aluminium alloy sheets and copper sheets with dimensions of $120 \mathrm{~mm} \times$ $80 \mathrm{~mm} \times 1 \mathrm{~mm}$ and $80 \mathrm{~mm} \times 80 \mathrm{~mm} \times 1 \mathrm{~mm}$, respectively. The chemical compositions of 6061 aluminium alloy are shown in Table 1 . The surfaces of the aluminium and copper were polished with emery paper of grade 800 and cleaned with acetone before welding. As illustrated in Fig. 2a, the aluminium alloy sheet was placed at the top of the pure copper sheet. A pure $\mathrm{Zn}$ foil with dimensions of $100 \mathrm{~mm} \times 20 \mathrm{~mm} \times 0.2 \mathrm{~mm}$ was placed between the aluminium and copper plates along the welding direction.

The dimensions of the specimen for tensile test are detailed in Fig. 2b. The tensile strength was defined as the maximum load at fracture during tensile testing divided by the lap area of the test sample.

During the joining process, the temperature of the joint was recorded vertically by K-type thermocouples (KT). To detect a more accurate temperature in the welding region, the K-type thermocouple was embedded in the $\mathrm{Cu}$ plate underneath the welding line, as indicated in Fig. 2. Based on the welding experiments, the interfacial layer structures were observed via an optical microscope and a scanning electron microscope (SEM). The characteristics and causes of this interlayer were analysed using the energy-dispersive X-ray spectroscopy (EDS) and X-ray diffraction (XRD). A shear tensile test was carried out at room temperature at a crosshead speed of $1 \mathrm{~mm} / \mathrm{min}$ by using an electronic universal tensile testing machine.

\subsection{Selection of Welding Parameters}

According to the above, four parameters (tool diameter, travel speed, rotation speed and plunge depth) were selected as the main factors in welding. Four levels were
Table 2 Welding parameters and their levels

\begin{tabular}{llllll}
\hline Factor & Parameters & Level 1 & Level 2 & Level 3 & Level 4 \\
\hline A & $\begin{array}{c}\text { Shoulder parameter } \\
(\mathrm{mm})\end{array}$ & 7 & 10 & 12 & 15 \\
& Rotation speed (rpm) & 8000 & 10,000 & 12,000 & 14,000 \\
B & Travel speed (mm/min) & 50 & 100 & 150 & 200 \\
C & Plunge depth (mm) & 0.05 & 0.1 & 0.15 & 0.2 \\
D &
\end{tabular}

considered in each parameter, as shown in Table 2. Thus, an L16 $\left(4^{5}\right)$ orthogonal array table was consulted to determine which experiments to conduct. The experimental layout using the L16 orthogonal array is shown in Table 3.

The shear tensile strength (STS) values obtained in the shear tensile tests are tabulated in Table 3. These values illustrate that the maximum STS was $17.12 \mathrm{MPa}$ for the sample in experiment $11\left(\mathrm{~A}_{3} \mathrm{~B}_{3} \mathrm{C}_{1} \mathrm{D}_{2}\right)$. However, the parameter may not be optimal, which motives the further analysis for optimal parameter selection.

The range method is suitable for analysing the degree of influence of each factor on the test target and determining the optimal test plan. The formula is shown as:

$R_{i}=\overline{T_{i j}}(\max )-\overline{T_{i j}}(\min )$,

where $i$ is the factor; $j$ is the level; $T_{i j}$ represents the sum of the tests corresponding to the factor of column $i$ and the level of $j$; $\overline{T_{i j}}$ represents the average value of $T_{i j}$; and $R_{i}$ represents the extreme difference in the factor of column $i$.

Table 4 shows the ranges of each factor. It was observed that the shoulder diameter was the most important factor in terms of the tensile force compared with the rotation speed, travel speed and plunge depth. At the same time, the level corresponding to the maximum value of each column of $T_{i j}$ in Table 4 is the optimal level of factor $i$. 
Table 3 Experimental layout using the $\mathrm{L}_{16}\left(4^{5}\right)$ orthogonal array

\begin{tabular}{lllllll}
\hline Group & Factor A & Factor B & Factor C & Factor D & Error & STS (MPa) \\
\hline 1 & 1 & 1 & 1 & 1 & 1 & 0 \\
2 & 1 & 2 & 2 & 2 & 2 & 0 \\
3 & 1 & 3 & 3 & 3 & 3 & 0 \\
4 & 1 & 4 & 4 & 4 & 4 & 0 \\
5 & 2 & 1 & 2 & 3 & 4 & 10.46 \\
6 & 2 & 2 & 1 & 4 & 3 & 11.77 \\
7 & 2 & 3 & 4 & 1 & 2 & 0 \\
8 & 2 & 4 & 3 & 2 & 1 & 9.34 \\
9 & 3 & 1 & 3 & 4 & 2 & 15.68 \\
10 & 3 & 2 & 4 & 3 & 1 & 15.43 \\
11 & 3 & 3 & 1 & 2 & 4 & 17.12 \\
12 & 3 & 4 & 2 & 1 & 3 & 13.96 \\
13 & 4 & 1 & 4 & 2 & 3 & 7.01 \\
14 & 4 & 2 & 3 & 1 & 4 & 7.33 \\
15 & 4 & 3 & 2 & 4 & 1 & 9.68 \\
16 & 4 & 4 & 1 & 3 & 2 & 8.13 \\
\hline
\end{tabular}

Table 4 Results of range analysis of the orthogonal test (MPa)

\begin{tabular}{lllll}
\hline & $\mathrm{A}$ & $\mathrm{B}$ & $\mathrm{C}$ & $\mathrm{D}$ \\
\hline$\overline{T_{i 1}}$ & 0 & 8.292 & 9.259 & 5.323 \\
$\overline{T_{i 2}}$ & 7.897 & 8.636 & 8.528 & 8.369 \\
$\overline{T_{i 3}}$ & 15.550 & 6.701 & 8.091 & 8.510 \\
$\overline{T_{i 4}}$ & 8.043 & 7.861 & 5.611 & 9.287 \\
$R_{i}$ & 15.550 & 1.935 & 3.648 & 3.964 \\
\hline
\end{tabular}

Therefore, the optimal parameter combination is theoretically $\mathrm{A}_{3} \mathrm{~B}_{2} \mathrm{C}_{1} \mathrm{D}_{4}$.

Generally, the larger the lap area, the higher the welding strength becomes. However, the maximum tensile strength appeared when using a $12 \mathrm{~mm}$ shoulder instead of a $15 \mathrm{~mm}$ shoulder. Therefore, to explain this phenomenon, another experiment was implemented. In this experiment, the shoulder diameter was set as the research object, and the optimal parameters $\left(\mathrm{B}_{2} \mathrm{C}_{1} \mathrm{D}_{4}\right)$ were used. Four shoulder diameters $-7 \mathrm{~mm}, 10 \mathrm{~mm}, 12 \mathrm{~mm}$ and $15 \mathrm{~mm}$-were selected. To keep it simple, they are defined as D7, D10, D12 and D15, respectively. The details will be discussed in the following chapters.

\section{Results}

\subsection{Characteristics of Welding Process Parameters}

\subsubsection{Temperature and Axial Force}

The real-time temperature changing curves of D7, D10, D12 and D15 are shown in Fig. 3a. The peak temperatures of all samples during the FSB process were higher than the melting point of $\mathrm{Zn}$, which is the horizontal line indicated in Fig. 3a. Furthermore, the residence time under temperatures above the melting point of $\mathrm{Zn}$ increased with the increase in the shoulder diameter, which may influence the macrostructure and the compounds in the interface.

The axial force in the welding process was also obtained (as shown in Fig. 3b). Obviously, the axial force increased with the augmentation of the shoulder diameter. Compared with conventional FSW axial force curves [20], the shapes of the FSB curves are similar, while their values are lower, which was caused by the ultrahigh rotation speed [19]. The maximum axial force was only $1.4 \mathrm{kN}$ for sample D15, which is lower than that $(11 \mathrm{kN})$ in conventional FSW with a low rotation speed of $1600 \mathrm{rpm}$ [21]. It is obvious that an ultrahigh rotation speed greatly reduces the axial force in the welding process, which inevitably leads to changes in the weld appearance and interface. Therefore, the effects of different shoulders on the structure at an ultrahigh rotation speed will be introduced in the next chapter.

\subsubsection{Forward Resistance and Lateral Force}

The forward resistance and lateral force of the friction tool during the welding process were detected as shown in Fig. 1. 
(a)

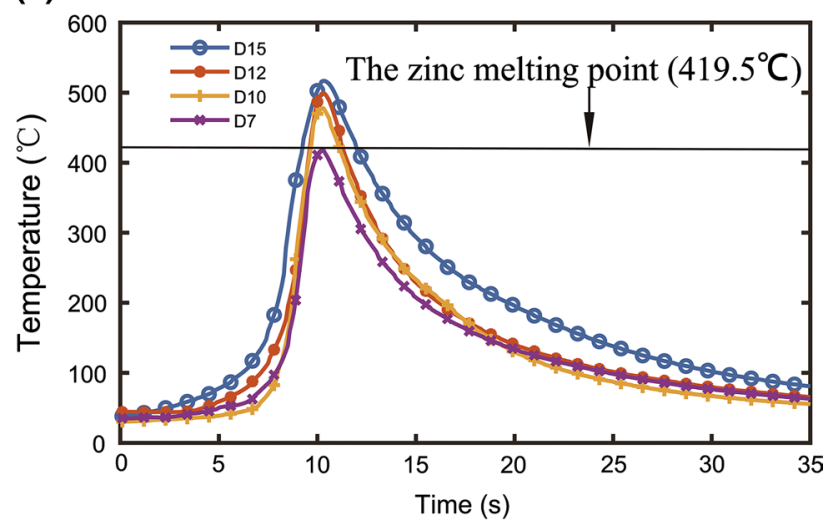

(b)

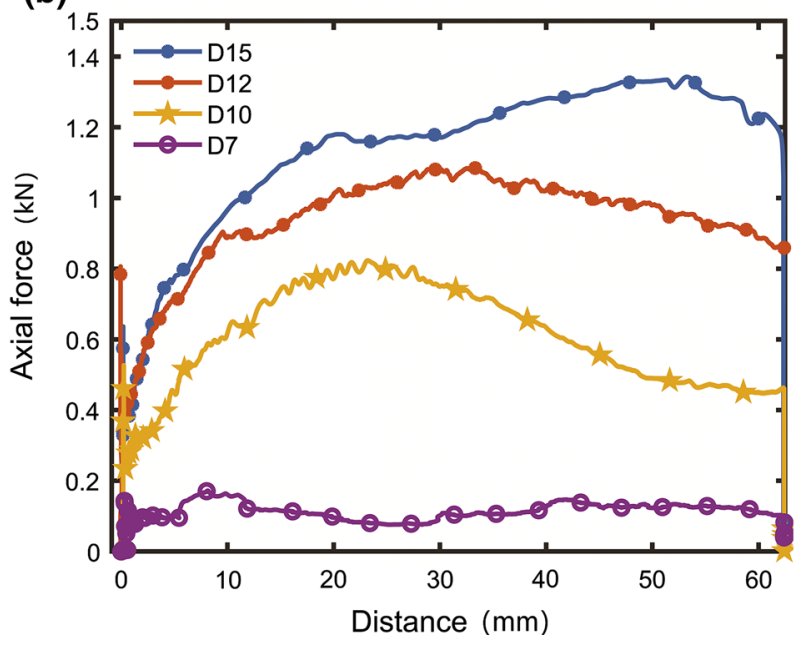

Fig. 3 Temperature histories at one point $\mathbf{a}$ and axial force histories for the whole process $\mathbf{b}$

The change histories of the forward resistance and lateral force (D7) are displayed in Fig. 4. In detail, both of the forces varied with the regularity of the oscillations, and the oscillation frequency was the same as the rotational frequency.
Additionally, there was a phase difference between the two forces, with the lateral force in advance of the forward resistance (Fig. 4b). The phase difference in this study is the phase of the forward resistance minus the phase of the lateral force. For other tool diameters, the curves show similar regularity.

The results of the two forces are shown in Fig. 5. The magnitude of the net force increased with the augmentation of the shoulder diameter as well as the axial force. Fourier transform was used to obtain the oscillation frequency and amplitude. The main oscillation frequency of the axial force was $42 \mathrm{~Hz}$, and the oscillation amplitudes were $0.15 \mathrm{kN}$ (D7), $0.08 \mathrm{kN}$ (D10), $0.088 \mathrm{kN}$ (D12), and $0.09 \mathrm{kN}$ (D15). Meanwhile, the resultant force had the same oscillation frequency as that of the friction tool $(167.7 \mathrm{~Hz})$, and the oscillation amplitude was $0.008 \mathrm{kN}$ for the four different samples.

\subsection{Macrostructure Features of the Joints}

The appearances of the four samples and their phase difference histories during the welding process are shown in Fig. 6. Obviously, flashes were observed in all samples, especially in D7, D10 and D12. Additionally, the flashes decreased with increasing the shoulder diameter, which may be related to the plunging depth of the shoulder. With an angle of $1.5^{\circ}$ between the central axis and the vertical line, an increase in the shoulder diameter resulted in a larger shoulder area without any inserting material, which led to an increase in the amount of material that can be accommodated [22]. The shoulder was completely inserted into the aluminium in sample D7, which was the cause of the huge flash in sample D7. At the same time, the surface of the aluminium in the weld area had a scale-like ripple.

The magnitude of the resultant force increased with the increase in the tool diameter (Fig. 5a). At the same time, more $\mathrm{Zn}$ filler was extruded with the increase in the tool diameter (Fig. 7). The intensity of the oscillation contributed to the flow of the $\mathrm{Zn}$ filler. With the further
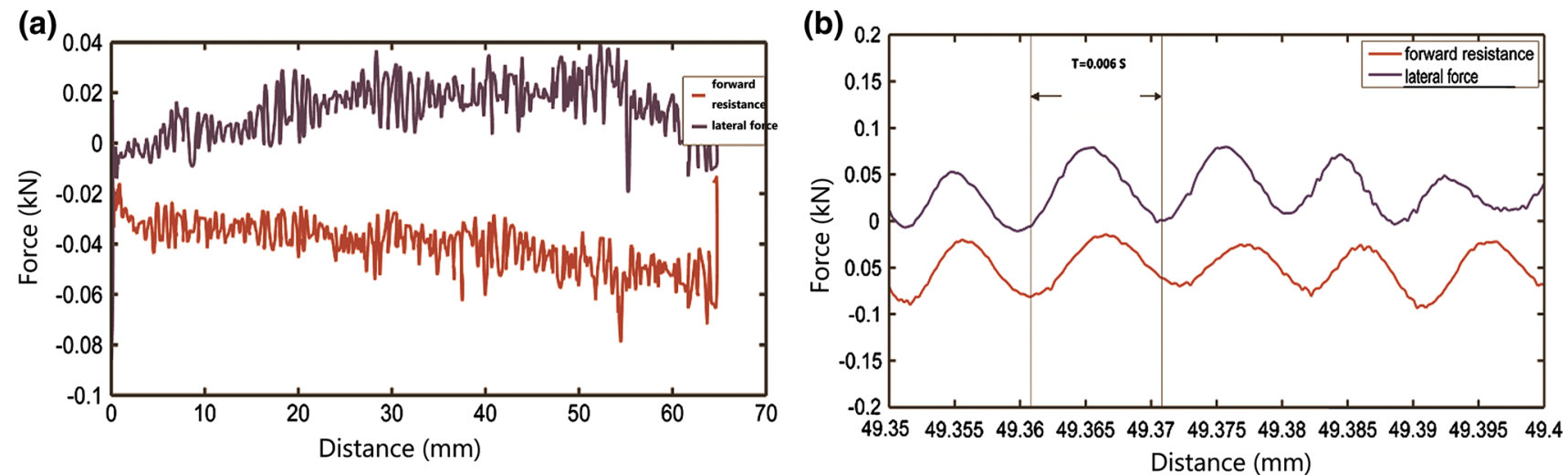

Fig. 4 Distribution of the forward resistance and lateral force $\mathbf{a}$ and variation in detail $\mathbf{b}$ 

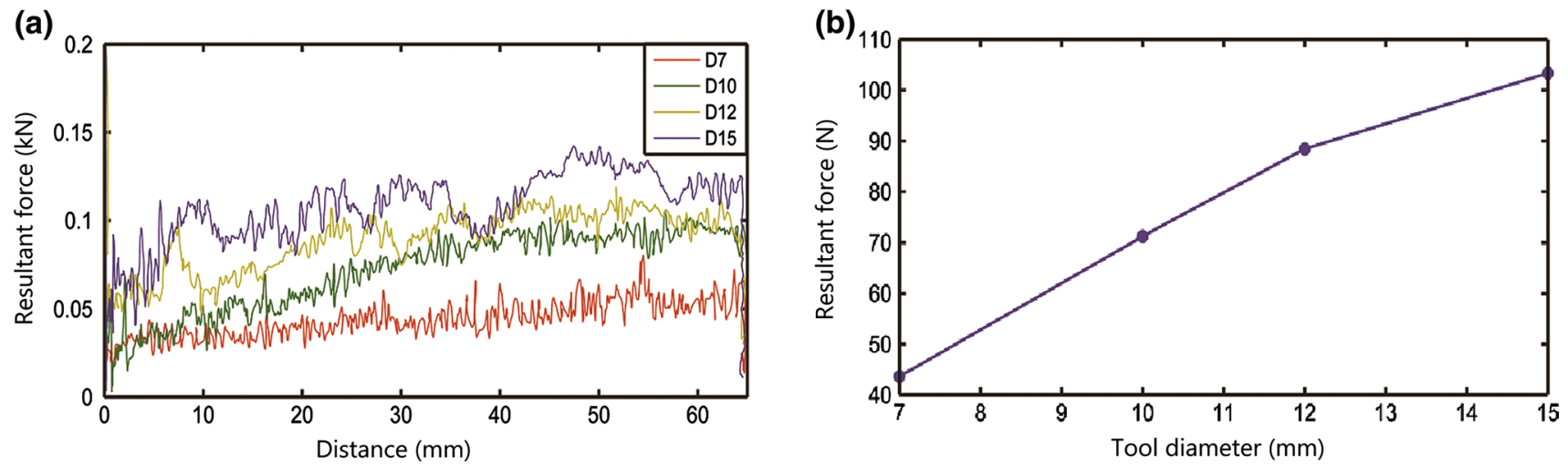

Fig. 5 Resultant force histories for the whole process $\mathbf{a}$ and the average of the resultant force for different tool diameters $\mathbf{b}$
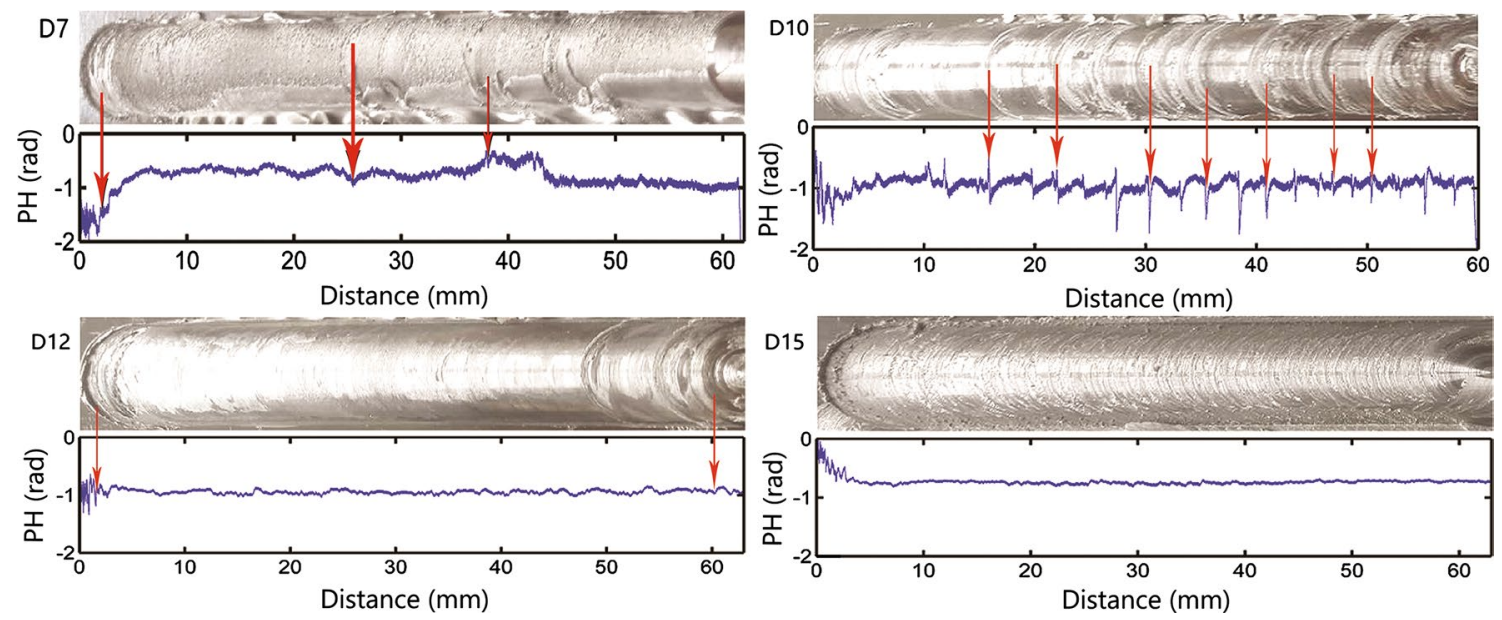

Fig. 6 Weld surfaces and phase difference curves for different tool diameters

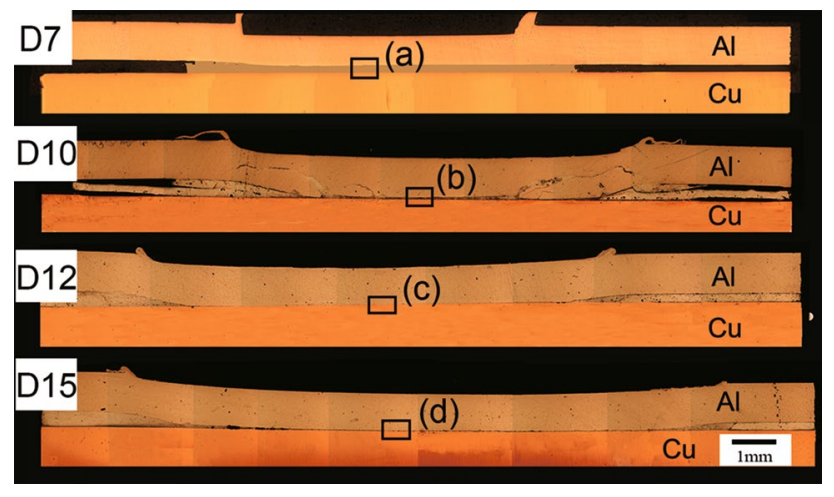

Fig. 7 Macrostructures of the cross sections of pin-less FSW with a Zn metal filler produced

investigations, the thickness of the interlayer between the upper $\mathrm{Al}$ plate and the bottom $\mathrm{Cu}$ plate decreased with an increase in the shoulder diameter. When the shoulder diameter was $7 \mathrm{~mm}$, the thickness of the interlayer was approximately $150 \mu \mathrm{m}$, which demonstrates that the $\mathrm{Zn}$ filler was not extruded or forged during the FSW process. For sample D10, the thickness was approximately $100 \mu \mathrm{m}$. The grey area is shown in Fig. $7 b$, which indicated that the temperature and axial force were suitable to melt the zinc and not extrude it. However, the thickness decreased obviously in the other samples, especially D15, in which the thickness decreased to approximately $7 \mu \mathrm{m}$.

Based on the temperature and axial force curves, the cause of the variation in the thickness with the shoulder diameter is obvious. Upon increasing the shoulder diameter, the maximum temperature and axial force were also increased, which resulted in melting of the zinc foil and extrusion of the liquid zinc out of the welding zone. Additionally, the element diffusion and the microstructure in the interlayer might also be impacted. 


\subsection{Mechanical Properties of the Joint}

The shear strengths and shear forces of the joints brazed by different shoulder diameters are shown in Fig. 8a. According to the figure, the shear strength increased and then decreased with increasing the shoulder diameter. The maximum shear strength (18.67 MPa) was found in sample D12, which fractured at the HAZ of the aluminium sheet, as shown in Fig. 8b. The lowest strength (8 MPa) was found in sample D7. Fractography of the copper surface was performed on the four samples produced with different shoulders, as shown in Fig. 9. As mentioned, sample D12 fractured at the HAZ of the aluminium sheet. Therefore, the fracture surface was obtained by using a chisel and hammer. It can be seen that all of the copper surfaces were covered with a grey substance, but there was less of the substance on the D7 surface, which indicated that the interfacial layers were the sources of the tensile failure. In other words, the shear strength of $\mathrm{Cu} / \mathrm{Al}$ joints was related to the interfacial $\mathrm{Cu}$ layer. Another noteworthy aspect in Fig. 9 is the semicircular marks on the fracture surface of D12, as shown in Fig. 9c. The torquing effect was shown to enhance due to the intense deformation under the larger shoulder, which caused the liquid metal in the interlayer to mix completely. However, this phenomenon could not be observed on the fracture surface of sample D15, since the zinc was squeezed out and was too thin to stir.

\section{Discussion}

\subsection{Influencing Factors of the Weld Surface}

The relationship between the weld surface and the phase difference is given in Fig. 6. Three scale-like ripples appeared on the joint of sample D7, and the mutations were shown on the phase difference curve at the same location (Fig. 6a). At the same time, where there were extremely deep scale-like ripples on the weld area of sample D10, there were sharp angles on the curve (Fig. 6b). The first part of the D12 joint looked glabrous, while some scale-like ripples appeared at the end, and the phase difference curve showed the same features (Fig. 6c). The curve of D15 became smooth, and (a)

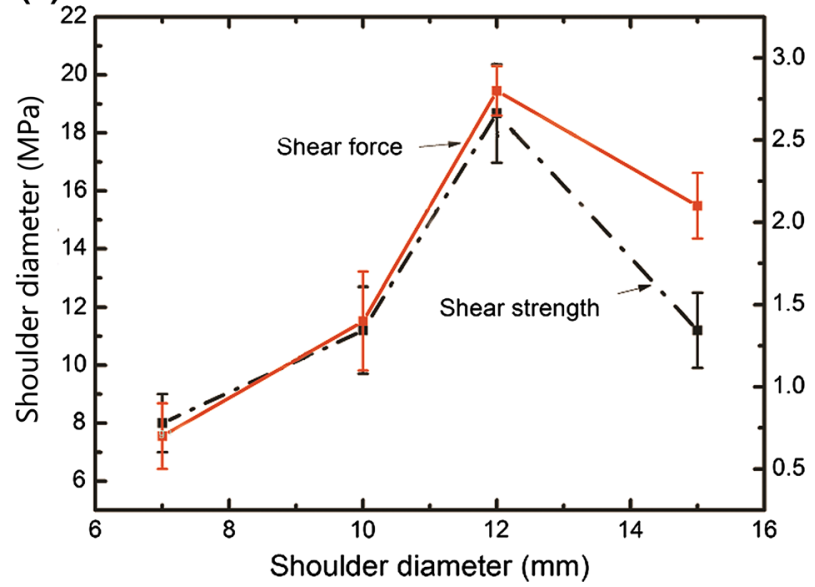

(b)

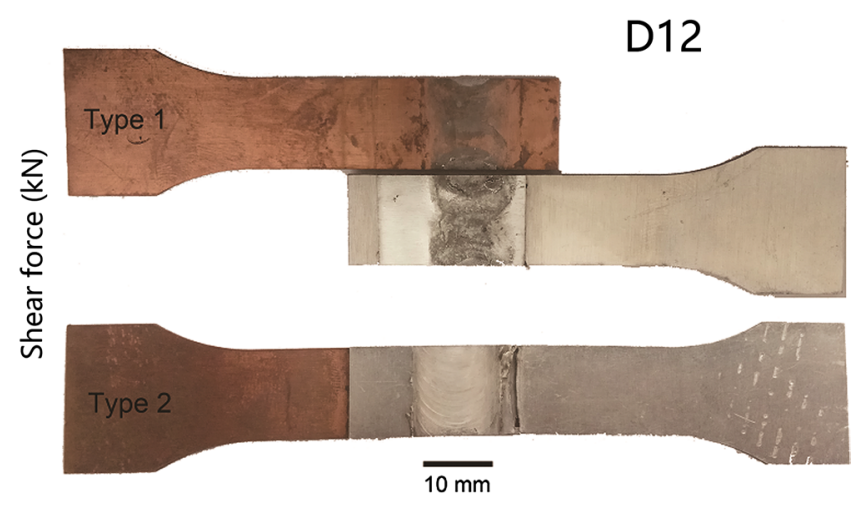

Fig. 8 Tensile test results of the average tensile strength $\mathbf{a}$ and depictions of the two fracture types $\mathbf{b}$
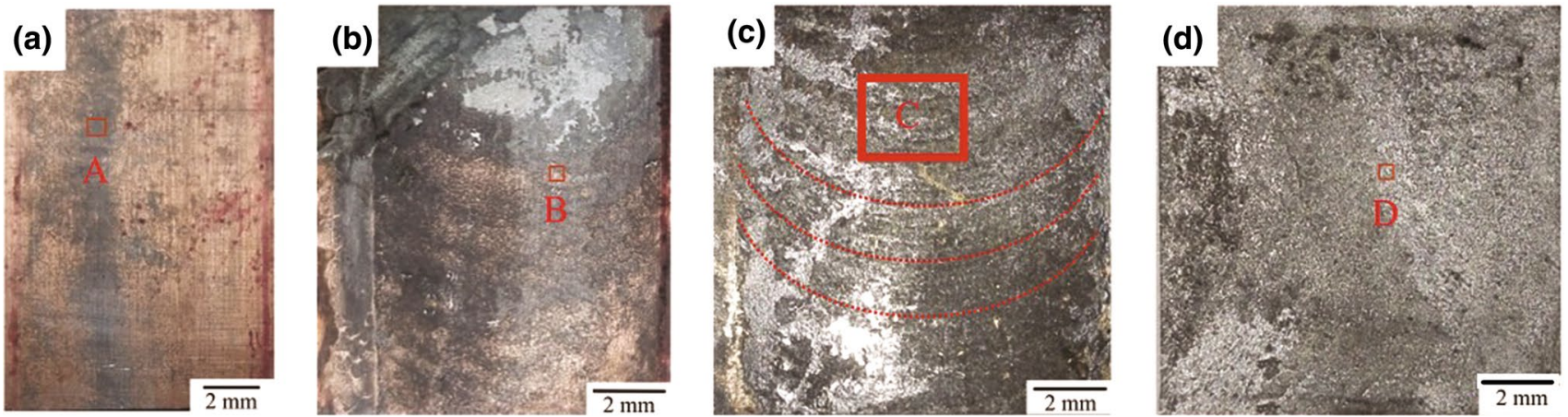

Fig. 9 Overall images of the $\mathrm{Cu}$ side of the fracture surface for different shoulder diameters: a D7, b D10, c D12, d D15 
the scale-like ripples on the joints were insignificant, with the appearance becoming smooth (Fig. 6d). When there were angles on the phase difference curves, scale-like ripples appeared on the weld area. Furthermore, the sharper were the angles, the deeper were the scale-like ripples.

Generally, the forward resistance changes with the hardness of the metal at the front of the tool. In the two adjacent stationary periods, the amount of plastic metal flowing during every period is approximately the same. When the hardness of the metal at the front of the friction tool increases, the degree of metal plasticization is insufficient, and the forward resistance increases. There is not enough plastic metal to be transferred to the backward side; thus, the lateral force decreases, and the continuous scale-like ripples on the surface are interrupted. Until the metal is fully plasticized, a large amount of plastic metal is immediately filled into the stirring path, forming wide scale-like ripples, and the lateral force comes to a peak. This is the cause of the phase difference and the formation of wide scale-like ripples.

\subsection{Relationship Between the Interlayer and the Axial Force, Forward Resistance and Lateral Force}

As mentioned above, the original zinc foil was found in the interface of sample D7, which is shown in Fig. 10a and is identified via EDS of point $\mathrm{B}$. The causes were that the axial force was small (Fig. 3b) and the forward resistance and lateral force were not sufficient. The energy of the resultant force oscillation was unable to make the melted zinc flow well. In the vicinity of the aluminium zones, a grey homogeneous zone was found and cracks could be clearly observed, which was identified as Al-Zn eutectic material by EDS. Similar structures were found in the other samples, such as in D10 (points D and G), D12 (point $\mathrm{H}$ ) and D15 (point $\mathrm{J}$ ). This type of structure could form easily, since the eutectic melting point was low $\left(381{ }^{\circ} \mathrm{C}\right)$ for an $\mathrm{Al}-\mathrm{Zn}$ reaction, as seen in its binary phase diagram [20]. Therefore, it was likely that molten $\mathrm{Zn}$ reacted with the faying $\mathrm{Al}$ surface, which melted locally to create an Al-Zn eutectic structure. The chemical composition of the reaction layer near the copper base metal was also detected by EDS analysis at point $\mathrm{C}$, with the results shown in Table 5. Based on the ratio of the atomic composition given by the EDS results, the intermetallic layer formed was probably $\mathrm{CuZn}_{5}$. It is well known that $\mathrm{CuZn}_{5}$ can easily be formed at a temperature of $425^{\circ} \mathrm{C}$ compared to other compounds [23]. Considering that the original zinc existed at the interface, the aluminium could not diffuse into the copper. Therefore, $\mathrm{CuZn}_{5}$ readily formed near the copper side. However, the interface of sample D10 shows heterogeneous compounds in Fig. 10b. Compared
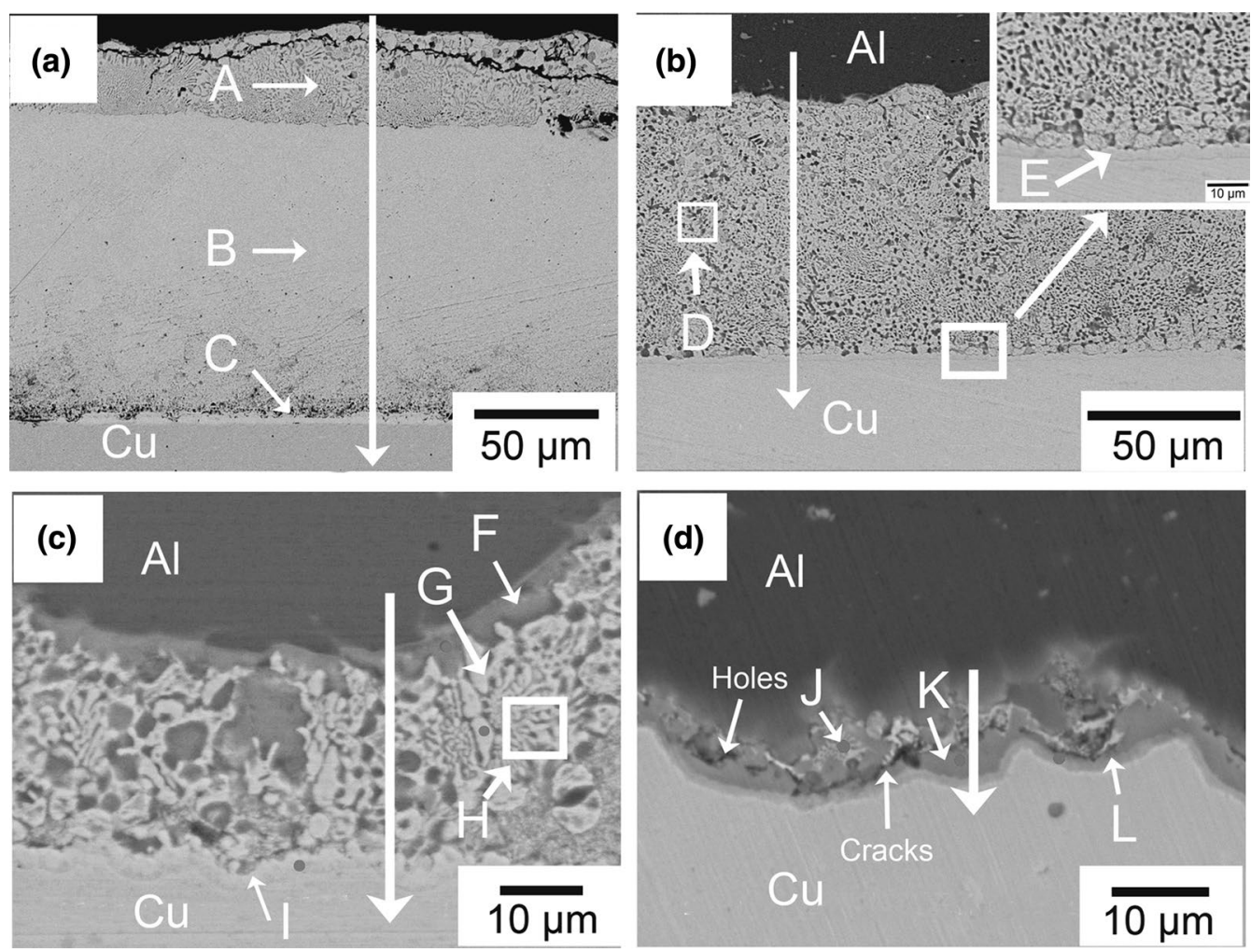

Fig. 10 SEM images of the Al/Zn/Cu interlayer produced by FSB under different shoulder diameters: a D7; b D10; c D12, d D15 
Table 5 Element compositions and possible phase constitutions of the regions marked in Fig. 10

\begin{tabular}{|c|c|c|c|c|c|}
\hline \multirow[t]{2}{*}{ Sample } & \multirow[t]{2}{*}{ Regions } & \multirow[t]{2}{*}{ at. $\%$} & \multirow[t]{2}{*}{ Phase } & \multicolumn{2}{|c|}{ Oscillation amplitude } \\
\hline & & & & Axial & Resultant force \\
\hline \multirow[t]{3}{*}{ D7 } & A & $33.35 \mathrm{Al}-77.65 \mathrm{Zn}$ & Al-Zn eutectic & 0.15 & 0.008 \\
\hline & B & $100 \mathrm{Zn}$ & Pure Zn & & \\
\hline & $\mathrm{C}$ & $19.74 \mathrm{Cu}-80.26 \mathrm{Zn}$ & $\mathrm{CuZn}_{5}$ & & \\
\hline \multirow[t]{2}{*}{ D10 } & $\mathrm{D}$ & $39.63 \mathrm{Al}-10.27 \mathrm{Cu}-50.1 \mathrm{Zn}$ & $\mathrm{Al}-\mathrm{Zn}$ eutectic & 0.08 & 0.008 \\
\hline & $\mathrm{E}$ & 7.52Al-20.74Cu-71.74Zn & $\mathrm{CuZn}_{5}$ & & \\
\hline \multirow[t]{4}{*}{ D12 } & $\mathrm{F}$ & $83.54 \mathrm{Al}-1.84 \mathrm{Cu}-14.63 \mathrm{Zn}$ & $\alpha-\mathrm{Al}$ & 0.088 & 0.008 \\
\hline & $\mathrm{G}$ & $6.32 \mathrm{Al}-22.14 \mathrm{Cu}-71.53 \mathrm{Zn}$ & $\mathrm{CuZn}_{5}$ & & \\
\hline & $\mathrm{H}$ & $22.26 \mathrm{Al}-12.44 \mathrm{Cu}-65.3 \mathrm{Zn}$ & Al-Zn eutectic & & \\
\hline & I & $3.47 \mathrm{Al}-19.59 \mathrm{Cu}-76.94 \mathrm{Zn}$ & $\mathrm{CuZn}_{5}$ & & \\
\hline \multirow[t]{3}{*}{ D15 } & $\mathrm{J}$ & $37.7 \mathrm{Al}-12.2 \mathrm{Cu}-50 \mathrm{Zn}$ & $\mathrm{Al}-\mathrm{Zn}$ eutectic & 0.09 & 0.008 \\
\hline & $\mathrm{K}$ & $67.26 \mathrm{Al}-31.77 \mathrm{Cu}-0.97 \mathrm{Zn}$ & $\mathrm{Al}_{2} \mathrm{Cu}$ & & \\
\hline & $\mathrm{L}$ & $46.6-48.62 \mathrm{Cu}-4.78 \mathrm{Zn}$ & $\mathrm{Al}_{4.2} \mathrm{Cu}_{3.2} \mathrm{Zn}_{0.7}$ & & \\
\hline
\end{tabular}

with sample D7, sample D10 shows a completely different microstructure. The original zinc could hardly be found in the interlayer and was replaced by a lamellar $\mathrm{Zn}-\mathrm{Al}$ eutectic phase. The fully developed homogeneous structure near the copper surface is shown by the inset image in Fig. 10b. It is similar to the microstructure of point $\mathrm{C}$ in Fig. 10a, the chemical composition of which is shown in Table 5, with the material identified as $\mathrm{CuZn}_{5}$.

Upon increasing the shoulder diameter to $12 \mathrm{~mm}$ (Fig. 10c), the size and volume fraction of the $\alpha-\mathrm{Al}$ and $\mathrm{CuZn}_{5}$ phases both remarkably increased, accompanied by a volume fraction decreasing in the $\mathrm{Zn}-\mathrm{Al}$ eutectic phase. Furthermore, the black $\alpha$-Al grew along the aluminium surface in continuous form and precipitated in the $\mathrm{Zn}-\mathrm{Al}$ eutectic phase. The $\mathrm{CuZn}_{5}$ phase, which confirmed by XRD as shown in Fig. 11a, not only was discovered along the copper surface but also found at the interlayer in bulk form around the $\mathrm{Zn}-\mathrm{Al}$ eutectic phase.

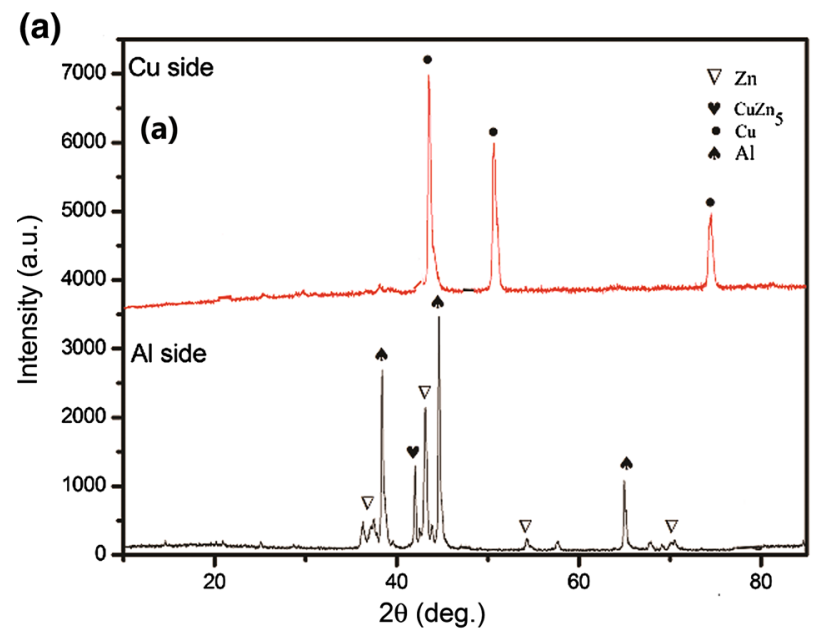

The SEM image of the interlayer of sample D15 is shown in Fig. 10d. Holes and cracks were clearly found in the image. Moreover, compared with the samples of D10 and D12, the interlayer showed a completely different microstructure. Some brittle IMCs were found, such as those at points $\mathrm{K}$ and $\mathrm{L}$ near the interfacial regions of copper. The XRD patterns of the fracture surface of the aluminium and copper in sample D15 are shown in Fig. 11b. The filler metal layer was composed of $\mathrm{Al}_{2} \mathrm{Cu}, \mathrm{CuZn}$ and $\mathrm{Al}_{4.2} \mathrm{Cu}_{3.2} \mathrm{Zn}_{0.7}$ phases. The IMC $\mathrm{Al}_{2} \mathrm{Cu}$ can be formed due to two reasons. The first one is that the ultrahigh rotation speed FSB used in this study has the potential to reach the lowest $\mathrm{Al}-\mathrm{Cu}$ eutectic melting point of $548.2{ }^{\circ} \mathrm{C}$ [24] and maintain it for as short as $0.2-0.5 \mathrm{~s}$. And the other one is the highest axial force, which results in little retained zinc in the interface and leads to direct contact between the aluminium and copper to form $\mathrm{Al}_{2} \mathrm{Cu}$. On the other hand, the IMC $\mathrm{Al}_{4.2} \mathrm{Cu}_{3.2} \mathrm{Zn}_{0.7}$ formed near the copper surface. Xiao et al. [25] reported

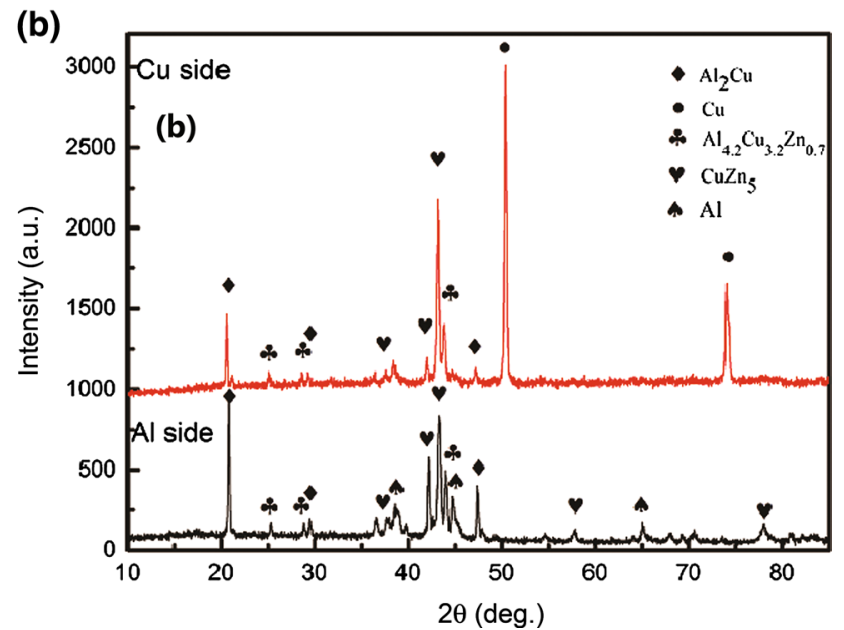

Fig. 11 XRD patterns detected from the shear fracture surface of the copper side and the aluminium side after a shear test: a D12, b D15 
that $\mathrm{Al}_{4.2} \mathrm{Cu}_{3.2} \mathrm{Zn}_{0.7}$ was one of the first types of IMCs to precipitate when the elements in the melted filler metal were completely uniform.

With the increase in the magnitudes of the forward resistance and lateral force, the intermetallic compounds in the interface changed drastically. With the lowest magnitude generated for sample D7, the flow of plastic metal was not sufficient, and the original zinc foil was found in the interface. As the magnitudes of the forward resistance and lateral force increased, the original zinc foil was found to be missing. A lamellar $\mathrm{Zn}-\mathrm{Al}$ eutectic phase (D10) appeared, and the size and volume fraction of the $\alpha-\mathrm{Al}$ and $\mathrm{CuZn}_{5}$ phases both remarkably increased (D12), all of which contributed to the mechanical properties of the joint. At the magnitudes generated in D15, the magnitudes of the resultant force of the forward resistance and lateral force were much more intense than those from the other tools, which made the plastic metal flow too rapid, leading to holes and cracks.

To analyse the grey material and fracture form, the fracture surface images of the zones in Fig. 9 are shown in Fig. 12. In the joint of sample D7 as shown in Fig. 12a, the surface was mainly composed of $\mathrm{CuZn}_{5}$, which was also found in the cross section of sample D7. Additionally, the fracture presented an intergranular fracture pattern. It should be noted that there were few $\mathrm{CuZn}_{5}$ IMCs in the copper fracture surface. This result indicates that a crack can be created easily between the copper and $\mathrm{CuZn}_{5}$ when tension is located on the joint. Regarding the joint brazed by the 10-mm-diameter shoulder, the surface was composed of $\mathrm{CuZn}_{5}$ and $\mathrm{Al}-\mathrm{Zn}$ eutectic material. The morphology of the fracture also presented an intergranular fracture type. In contrast to the case for sample D7, Al-Zn eutectic material was found. Therefore, the crack was not only along the surface of the $\mathrm{CuZn}_{5}$ and $\mathrm{Al}-\mathrm{Zn}$ eutectic material but was also through the eutectic layer. For solid-state bonded joints of dissimilar metals, the joint strength is determined by two predominant factors, namely the intimate contact between the joining interfaces and the interfacial microstructure, particularly the formation of IMCs [26]. This result indicates that at a low welding temperature and low axial force, intimate contact between the copper and $\mathrm{CuZn}_{5}$ is not formed. In the joint brazed by a 12-mm-diameter shoulder, as shown in Fig. 12c, the morphology of the fracture presented a transgranular fracture pattern, which occurred in the $\mathrm{CuZn}_{5}$. As mentioned above, the $\mathrm{CuZn}_{5}$ was dispersed and distributed in the interlayer. Stress concentrations and crack defects are not easily produced in this structure. For sample D15, tensile failure happened at the root of the $\mathrm{Al}_{2} \mathrm{Cu}$ and $\mathrm{Al}_{4.2} \mathrm{Cu}_{3.2} \mathrm{Zn}_{0.5}$ on the $\mathrm{Cu}$ interface. It is well known that $\mathrm{Al}_{2} \mathrm{Cu}$ is a brittle IMC that easily becomes a stress concentration area with initial cracks and significantly decreases the mechanical properties of a joint $[9,27]$. Even more importantly, some cracks or holes
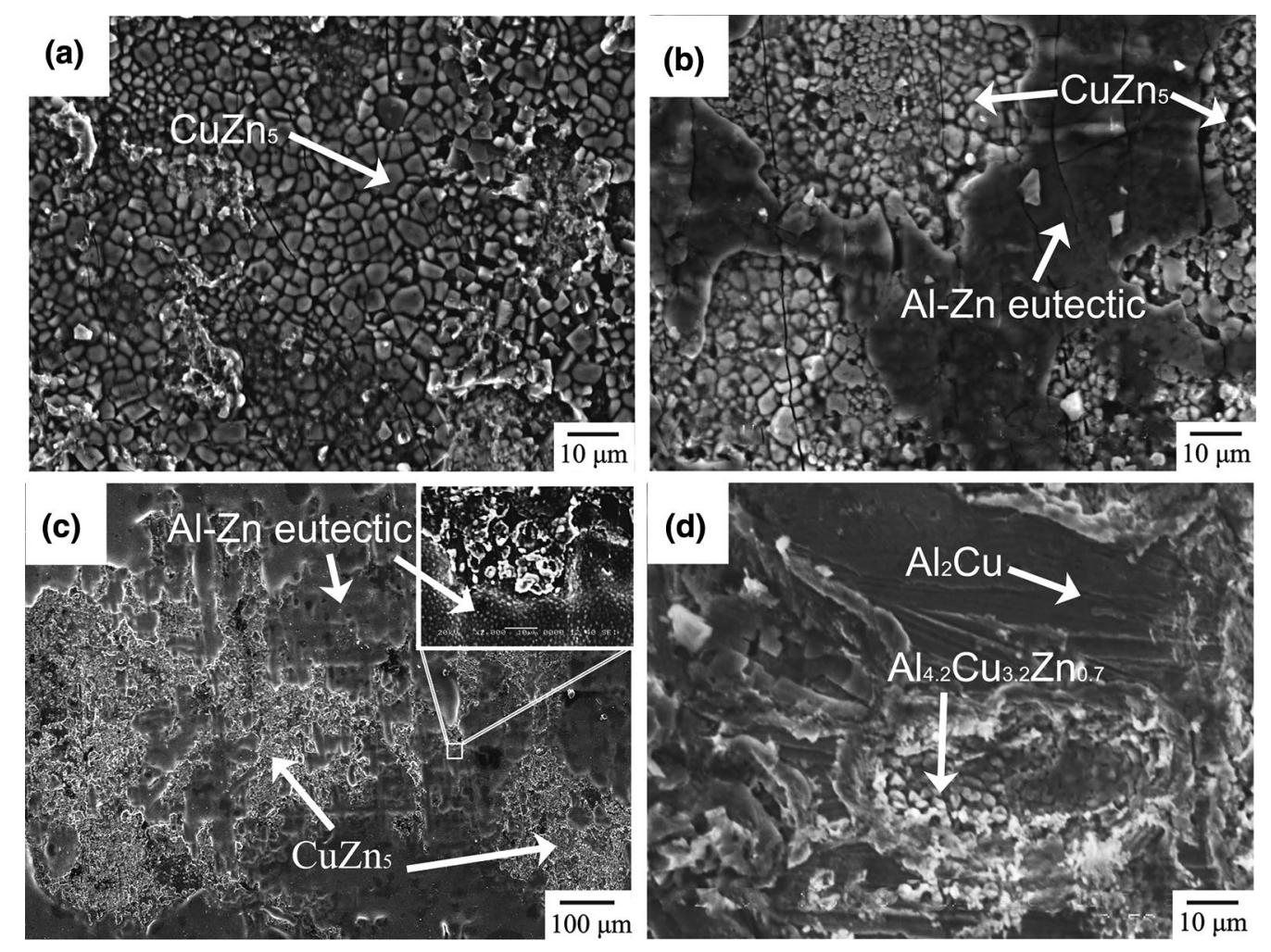

Fig. 12 SEM images of the Cu side of the fractured surface: a D7, b D10, c D12, d D15 
can be found in the interlayer that readily become the source of fracture. Therefore, the strength of the joint is degraded.

The oscillation of the resultant force improved the mechanical properties of the joint, as well as the ultrasound assistance [17]. The appropriate flow of plastic metal during the welding process yielded satisfactory properties of the joints. When the plastic metal flew too vigorously, cracks and holes appeared, which defeated the mechanical properties of the joint.

\section{Conclusions}

$\mathrm{Al} / \mathrm{Cu}$ lap joints were obtained by using zinc as the interlayer with ultrahigh rotation speeds. The influence of different process parameters (rotation speed, travel speed, plunge depth and shoulder diameter) on the welding quality was analysed. Besides, the effects of the axial force, forward resistance and lateral force produced by different shoulder diameters on the appearance of the weld area and the growth and distribution of IMCs in the middle layer at an ultrahigh rotation speed were analysed. The main conclusions are summarized as follows:

1. With a lower axial force and oscillation assistance, a satisfactory joint was obtained. Meanwhile, the shoulder diameter had a great influence on the mechanical properties of the welded joints.

2. The structure of the interlayer changed with an increase in the shoulder diameter. For sample D7, the middle layer was composed of an $\mathrm{Al}-\mathrm{Zn}$ eutectic layer, the original zinc layer and $\mathrm{CuZn}_{5}$ with a $2 \mu \mathrm{m}$ thickness because of the low temperature and small axial force. The joint brazing using a 12 -mm-diameter shoulder produced a largest lap shear tensile strength, since the interlayer had a mixed microstructure of $\mathrm{Al}-\mathrm{Zn}$ eutectic material and $\mathrm{CuZn}_{5} \mathrm{IMCs}$. Moreover, the joint failed in the HAZ, while the others fractured from the weld interface.

3. Ultrahigh rotation speed FSB with high-frequency oscillations and lower axial force contributed to yield satisfactory joints. The phase difference between the forward resistance and lateral force was related to the joint surface. When a sharp angle existed in the phase difference curve, obvious scale-like ripples appeared on the weld area. Additionally, the oscillation of the forward resistance and lateral force reflected the flow of plastic metal.

\section{References}

[1] Z.L. Hu, Q. Pang, M.L. Dai, Rare Met. 5, 1 (2018)

[2] B. Li, Y. Shen, L. Luo, W. Hu, Z. Zhang, Mater. Des. 49, 647 (2013)

[3] F.B. Argesi, A. Shamsipur, S.E. Mirsalehi, Acta Metall. Sin. (Engl. Lett.) 31, 1183 (2018)

[4] G.K. Padhy, C.S. Wu, S. Gao, J. Mater. Sci. Technol. 34, 1 (2018)

[5] C. Otten, U. Reisgen, M. Schmachtenberg, Weld. World. 60, 21 (2016)

[6] Z. Xue, S. Hu, J. Shen, D. Zuo, K.A. Jr, J. Laser. Appl. 26, 2002 (2013)

[7] R.N. Raoelison, T. Sapanathan, N. Buiron, M. Rachik, J. Manuf. Process. 20, 112 (2015)

[8] G.H. Carvalho, I. Galvão, R. Mendes, R.M. Leal, A. Loureiro, Sci. Technol. Weld. Join. 23, 501 (2018)

[9] C.Z. Xia, Y.J. Li, U.A. Puchkov, S.A. Gerasimov, J. Wang, Met. Sci. 25, 383 (2009)

[10] G.F. Zhang, K. Zhang, Y. Guo, J.X. Zhang, Metallogr. Microstruct. Anal. 3, 272 (2014)

[11] C. Xia, Y. Li, U.A. Puchkov, S.A. Gerasimove, J. Wang, Met. Sci. 23, 815 (2008)

[12] P. Xue, B.L. Xiao, D. Wang, Z.Y. Ma, Sci. Technol. Weld. Join. 16, 657 (2011)

[13] M.M. Khalilabad, Y. Zedan, D. Texier, M. Jahazi, P. Bocher, J. Manuf. Process. 34, 86 (2018)

[14] B. Kuang, Y. Shen, W. Chen, X. Yao, H. Xu, J. Gao, J. Zhang, Mater. Des. 68, 54 (2015)

[15] G. Huang, X. Feng, Y. Shen, Q. Zheng, P. Zhao, Mater. Des. 99, $403(2016)$

[16] A. Abdollah-Zadeh, T. Saeid, B. Sazgari, J. Alloys Compd. 460, $535(2008)$

[17] Y. Xiao, Study on The Metallurgic Bonding Mechanism and Properties of Liquid Phase Brazed Cu/Al Joints with The Assistance of Ultrasound, Ph.D. Thesis, Harbin Institute of Technology, 2014 (in Chinese)

[18] K.J. Quintana, J.L. Silveira, Int. J. Adv. Manuf. Technol. 96, 3993 (2018)

[19] S.J. Chen, Y. Zhou, J. Xue, R.Y. Ni, Y. Guo, J. Dong, J. Mater. Eng. Perform. 26, 1 (2017)

[20] E.Y. Ahn, H. Das, S.T. Hong, K.S. Han, M. Miles, K.J. Lee, J. Mech. Sci. Technol. 31, 3955 (2017)

[21] P. Sevvel, V. Jaiganesh, Trans. Indian Inst. Met. 68, 41 (2015)

[22] J.I. Murray, Bull. Alloy Phase Diagr. 4, 55 (1983)

[23] R. Balasundaram, V.K. Patel, S.D. Bhole, D.L. Chen, Mater. Sci. Eng. A 607, 277 (2014)

[24] C.Y. Chen, W.S. Huang, Mater. Trans. 48, 1938 (2007)

[25] Y. Xiao, H. Ji, M. Li, J. Kim, Mater. Sci. Eng. A 594, 135 (2014)

[26] G.F. Zhang, K. Zhang, L.J. Zhang, J.X. Zhang, Sci. Technol. Weld. Join. 19, 554 (2014)

[27] H. Liang, Y.A. Chang, J. Phase Equilib. Diffus. 19, 25 (1998) 